Article

\title{
Exploring the Influence of Drug Trafficking Gangs on Overdose Deaths in the Largest Narcotics Market in the Eastern United States
}

\author{
Nicole J. Johnson ${ }^{1, * \mathbb{C}}$, Caterina G. Roman ${ }^{1} \mathbb{D}$, Alyssa K. Mendlein ${ }^{1} \mathbb{C}$, Courtney Harding ${ }^{2}$, \\ Melissa Francis ${ }^{2}$ and Laura Hendrick ${ }^{3}$ \\ 1 Department of Criminal Justice, Temple University, Philadelphia, PA 19122, USA; \\ croman@temple.edu (C.G.R.); alyssa.mendlein@temple.edu (A.K.M.) \\ 2 Philadelphia Regional Office, Pennsylvania Office of the Attorney General, Philadelphia, PA 19153, USA; \\ csharding@attorneygeneral.gov (C.H.); mmfrancis@attorneygeneral.gov (M.F.) \\ 3 Philadelphia Field Division, Drug Enforcement Administration, Philadelphia, PA 19106, USA; \\ laura.a.hendrick@usdoj.gov \\ * Correspondence: njohnson@temple.edu
}

Received: 29 September 2020; Accepted: 4 November 2020; Published: 7 November 2020

\begin{abstract}
Research has found that drug markets tend to cluster in space, potentially because of the profit that can be made when customers are drawn to areas with multiple suppliers. But few studies have examined how these clusters of drug markets-which have been termed "agglomeration economies"- -may be related to accidental overdose deaths, and in particular, the spatial distribution of mortality from overdose. Focusing on a large neighborhood in Philadelphia, Pennsylvania, known for its open-air drug markets, this study examines whether deaths from accidental drug overdose are clustered around street corners controlled by drug trafficking gangs. This study incorporates theoretically-informed social and physical environmental characteristics of street corner units into the models predicting overdose deaths. Given a number of environmental changes relevant to drug use locations was taking place in the focal neighborhood during the analysis period, the authors first employ a novel concentration metric - the Rare Event Concentration Coefficient-to assess clustering of overdose deaths annually between 2015 and 2019. The results of these models reveal that overdose deaths became less clustered over time and that the density was considerably lower after 2017. Hence, the predictive models in this study are focused on the two-year period between 2018 and 2019. Results from spatial econometric regression models find strong support for the association between corner drug markets and accidental overdose deaths. In addition, a number of sociostructural factors, such as concentrated disadvantage, and physical environmental factors, particularly blighted housing, are associated with a higher rate of overdose deaths. Implications from this study highlight the need for efforts that strategically coordinate law enforcement, social service provision and reductions in housing blight targeted to particular geographies.
\end{abstract}

Keywords: drug markets; gangs; opioids; overdose; spatial concentration; generalized cross-entropy

\section{Introduction}

Urban areas in the United States, particularly those with high poverty levels, often experience two significant public health concerns: high levels of drug overdose deaths (OD) and gun violence. For some cities, these public health issues are intertwined and rise to epidemic proportions, greatly diminishing quality of life for residents and incurring billions of dollars in economic losses related to addiction treatment, criminal justice involvement, health care, and lost productivity. Particularly with open-air drug markets, research has noted that violence may emanate from drug trafficking 
gangs $^{1}$ and groups that compete for territory and clients (Harocopos and Hough 2012; Johnson 2016; Valasik and Tita 2018). In general, research has found that gang corners used for open-air drug distribution have high rates of violence, and rates are even higher if multiple gangs have contiguous or overlapping territories for drug distribution (Taniguchi et al. 2011).

Neighborhoods with many gang corners for drug distribution likely means more and easier access to illegal drugs for clients. Rather than competition driving away customers and driving down prices, research has shown that drug markets are another example of "agglomeration economies", which provide benefits by co-locating similar facilities (Taniguchi et al. 2009)—meaning more dealers, more customers, and more profit in one area. Coupled with the exponential growth in recent years of the illegal manufacturing and sale of fentanyl-a synthetic opioid 100 times more potent than morphine-and strict limits on prescription opioids, drug gangs have no shortage of clients seeking cheap options for opioids on the illegal market. Research confirms that increased availability of the typical street drugs such as heroin and cocaine, now supplemented or cut with fentanyl and its analogs, has led to increases in drug-related fatalities in many places, urban and rural alike (Armenian et al. 2018; Han et al. 2019).

In some areas, accidental deaths from overdose may be co-located with outdoor drug markets. Recent research suggests that many opioid misusers, in particular, use drugs near locations of drug purchase rather than at their homes (Bates et al. 2019; Metraux et al. 2019). Law enforcement reports and anecdotal evidence also suggest a contemporary link between drug market locations and deaths from drug overdose given the powerful lure of inexpensive drugs and high-quality heroin in some jurisdictions. Unsuspecting buyers may be purchasing more potent and dangerous substances, and using the drugs on the street soon after purchase, leading to accidental overdose (DEA 2018; Lieberman et al. 2020; Pardo et al. 2019). Research is needed that more closely examines the spatial nature of deaths caused by overdose and how overdose fatalities are related to the location of gangs that sell large quantities of drugs. There are potentially novel opportunities for coordinated policy responses that can address both issues simultaneously.

The current paper examines the spatial relationship between the locations of gangs that control drug trafficking and the locations of fatalities from accidental drug overdose. We apply the framework of environmental criminology (Brantingham and Brantingham 1981) to assess this relationship. We consider factors related to social disorganization theory (Shaw and McKay 1942) and the routine activities perspective (Cohen and Felson 1979) to provide context and opportunity for drug use and misuse tied to neighborhoods and places. We first explore the spatial dimensions of drug fatalities over a number of years, along with potential changes to help inform an environmental analyses of factors associated with OD locations.

We focus our study on a large area within the northeastern U.S. city of Philadelphia, Pennsylvaniathe neighborhoods of Fairhill and Kensington-where ODs and gun violence have been increasing steadily over the last five years. These neighborhoods, not surprisingly, are characterized by years of disinvestment, concentrated poverty, and poor physical conditions. The average income among residents of Kensington-Fairhill was $\$ 12,669$ for 2012 through 2016-approximately half of the average income for residents of Philadelphia as a whole (Confair et al. 2019). In these neighborhoods, all open-air drug markets are gang controlled, and tied to street corners. We seek to answer the following questions: Are ODs clustered around these drug trafficking organization (DTO)-controlled corners? Does the extent of clustering change over time or is it relatively stable? In addition to the DTO locations, what socioeconomic factors and physical environmental features of the landscape are associated with the location of ODs? We take into consideration how these DTO corners are nested within the larger ecological context of neighborhoods and how small areas can provide their own opportunities to attract

1 We use the terms "drug gang" and "drug trafficking organization" interchangeably in this work, although law enforcement agencies in Philadelphia more often use the term "drug trafficking organization" to describe the groups operating in this drug market. 
individuals seeking to purchase and use drugs. Overall, our intent is to advance the small, but growing literature on risky environments for substance use and misuse (Mennis et al. 2016), while specifying how particular constructs in environmental criminology can be integrated into that literature.

\section{Background}

\subsection{Drug Overdose Deaths and Philadelphia}

In the US, the number of ODs is four times higher today than it was in 1999, with overdoses representing the leading cause of injury-related death among adults (CDC 2020). The use of opioids is fueling the trend, which persists across all age groups, genders, and racial/ethnic groups (Olsen 2016). In Philadelphia, the increasing trend mirrors that of the U.S. as a whole. Among the largest U.S. cities, however, Philadelphia ranks at the top, with more ODs in 2019 than any big city, claiming 1150 victims (Whelan 2020).

The Kensington-Fairhill area of Philadelphia has been referred to as the largest open-air heroin market on the East Coast of the United States (Percy 2018) and data from the U.S. Federal Bureau of Investigation (FBI) confirm that Philadelphia is a leading regional and multistate supplier for high-grade heroin (Roselli 2018). The extensive reach of the Kensington-Fairhill area DTOs is evidenced by the amount of drugs from Kensington-Fairhill found outside of this area of the city-a three-month snapshot of victims of drug overdose from January through March of 2018 in the four counties surrounding Philadelphia identified fifteen different heroin stamps linked directly to Kensington suppliers (Roselli 2018).

Opiates such as heroin have increasingly been supplanted by synthetic opioids as a major driver of overdoses in Philadelphia and elsewhere (Pardo et al. 2019). Beginning in 2013, the U.S. as a whole has seen a large increase in ODs from synthetic opioids, largely illicitly-manufactured fentanyl. The influence of fentanyl on ODs cannot be overstated. Between 2013 and 2014, the age-adjusted rate of ODs from opiate pain relievers and heroin increased by $9 \%$ and $26 \%$ respectively, and the rate of death from fentanyl has seen large increases as well (Rudd et al. 2016). In 2018, fentanyl was the leading cause of opioid ODs in the U.S. over heroin and prescription painkillers (NIDA 2020). Similarly, the number of drugs seized by law enforcement in the U.S. that tested positive for fentanyl increased by 291\% between 2015 and 2017 (DEA 2019). Because profit potential and demand for opiates is so high in the U.S., it is not difficult to surmise that there are always heroin and fentanyl drug trafficking organizations and gangs willing to fill voids in production or supply left by changing legislation or enforcement efforts.

\subsection{Spatial Distribution of Overdose Deaths}

Although small-area geographic studies of crime and violence are common, studies examining the geographic distribution of ODs are not. This might be because drug misuse is theorized to be mostly attributed to individual-level and interpersonal factors, as opposed to environmental factors (Connell et al. 2010; Mennis et al. 2016). There is reason to believe that drug overdoses are not uniformly distributed throughout space, particularly given the inequitable distribution of what (Mennis et al. 2016) term "risky substance use environments" (p. 3). Offering a profile of these risky environments, the authors cite features of places that increase access to substances (such as environments in close proximity to illicit drug markets), high in disadvantage and disorder, or low in cohesion as facilitating drug use initiation or producing stressful conditions for which drug use is used as a coping mechanism (Mennis et al. 2016). Much aligned with the environmental criminology literature, they note that both detrimental and prosocial features of environments, such as density of alcohol establishments and high crime (detrimental), and access to greenspace, libraries and other public resources (prosocial), are inequitably distributed across communities, producing similar inequities in substance use and abuse. 
The rapidly-rising number of ODs associated with illegally-obtained opioids sold by drug trafficking gangs in Philadelphia creates a unique opportunity to test whether ecological structures and physical features of the environment help uncover spatial patterns that could have implications for policies and practices by criminal justice stakeholders as well as public health officials and practitioners. Furthermore, evidence of the concentration or co-location of two issues that have serious consequences for the well-being of communities would call for collaboration across government and community stakeholders.

We know from the criminological literature that open-air markets are associated with a variety of highly-visible problems, such as quality-of-life issues and violence (Harocopos and Hough 2012; Johnson 2016; Stevens and Bewley-Taylor 2009; Taniguchi et al. 2011). Studies conducted in Philadelphia at the Census block group level found that factors related to the social disorganization of neighborhoods (income level, vacant properties, female-headed households, residential instability, etc.) had more salience with regard to the location of drug markets than factors representing the routine activities perspective-such as the presence of attractors and generators of crime (McCord and Ratcliffe 2007). Research by Weisburd and colleagues examining environmental factors related to high-crime street segments found that street segments characterized by drug sales also experience high levels of social disorganization (Weisburd et al. 2010).

As ODs are being connected to drug-dealing locations, and there is evidence that opioid deaths cluster to a similar or even greater extent as compared to crime events (Carter et al. 2019), more research is being done to understand the environmental context of overdose deaths. Studies using relatively large units of analysis, such as the community or neighborhood, find clustering of ODs in relation to particular contextual and environmental features. In a 2005 study of 59 community districts (CDs) in New York City, Hembree and colleagues found a relationship between external and internal (e.g., windows, stairways, heating problems) environmental features of the neighborhood and accidental ODs. CDs that had more dilapidated or deteriorating buildings, window or stairway problems, structural fires, and housing with toilet, heating, or peeling paint issues were likely to have more ODs and those with a higher percentage of acceptably clean streets were likely to have fewer (Hembree et al. 2005), showing a potential facilitating role for the neighborhood-level physical environment in terms of ODs.

Recent research in Philadelphia by Johnson and Shreve (2020) examined the geographic distribution of drug overdose mortality at the ZIP code level, and found that fatal drug overdose counts significantly varied across ZIP codes. Testing constructs related to social disorganization, police surveillance, and physical environmental features, they found that overdose mortality was consistently related to neighborhood disadvantage and racial composition (percent White), and the overdose mortality of surrounding neighborhoods. In addition, overdose mortality was also positively associated with police activity for low-level crimes and with negative aspects of the built environment (unsafe and vacant housing, demolitions, and older housing stock) (Johnson and Shreve 2020). Other research has focused on units of analyses smaller than the neighborhood or ZIP code level, hypothesizing that place-based studies at the Census block group level or smaller are better able to capture important variation in places. A study by Li and colleagues (2019) used Census block groups to examine the relationship between features of the built environment with heroin-related emergency calls in Cincinnati, $\mathrm{OH}$ from 2015 to 2019. The authors found that, in addition to certain sociodemographic and population features (population age, gender, education, and median household income), heroin-related ODs were positively related to the proportion of parks and commercial, manufacturing, and downtown development zones within block groups. The distance to pharmacies also had a positive association with the emergency medical service (EMS) calls for drug overdose, while number of fast-food restaurants, distance to hospitals, and distance to opioid treatment programs were negatively associated with overdose mortality (Li et al. 2019).

Research has also studied these features at more than one environmental level to determine how spatial scales factored into overdose deaths. Headley Konkel and Hoffman (2020) examined the effects of both the neighborhood (block-level) and immediate (parcel-level) context on fatal drug overdoses in a non-urban Midwestern jurisdiction from 2014 to 2017. Using hierarchical linear modeling, they found 
that income inequality, residences of gang members, and the absence of bars predicted all overdoses at the block level, and sex offenses, drug arrests, and the presence of a drug house predicted ODs at the parcel level. They noted the counterintuitive finding related to bars, suggesting that the guardianship from bar management and the presence of other patrons may discourage illegal drug consumption.

In summary, the handful of studies seeking to uncover a relationship between overdose mortality and aspects of the physical and socioeconomic environment has demonstrated a link to certain environmental features, yet this research remains in its infancy, with studies using various units of analyses. Building on the work of the previous studies, we continue to apply a theoretical lens related to crime opportunity at places - in particular social disorganization theory and routine activity theory - to understand the importance of environmental factors for the anti-social behavior of drug misuse, with a focus on the location of drug trafficking gangs. Social disorganization theorists posit, and research has confirmed, that disadvantaged neighborhoods lack the ability to foster informal social control, thereby facilitating increased opportunities for crime (Bursik and Grasmick 1993). The routine activities perspective focuses more on how the daily routines of persons linked to places influence opportunity for crime. Daily patterns of life generate changes in the flow of potential victims and offenders that can facilitate or inhibit the opportunity for crime (Felson 1987, 1994). With regard to drug markets and accidental overdose, the victims are those purchasing and using drugs. In this study, most victims are traveling to the study area from other neighborhoods (Friedman et al. 2019). The perspective provides the framework to understand how facilities or block features can be attractors or generators for the establishment and maintenance of drug markets at corners-in effect increasing the likely convergence of dealers and purchasers/users (Taniguchi et al. 2009).

Federal and state law enforcement investigators in Philadelphia have noted the modus operandi of drug consumers is to use the product shortly after purchase, regardless of whether they are a walk-up or drive-up customer (Haigler and Francis 2020). The current study examines spatial relationships at a very small geographic level-the Thiessen polygon-to capture the unique contribution of the location of drug gangs to accidental ODs. The routine activities of DTOs would be closely tied to where targets (i.e., users) are located, creating an environment that is beneficial to both sellers and users. If these users consume dangerous drugs near their place of purchase, overdose mortality likely will be higher in places closer to point of sales, and likely clustered within an area closest to the majority of drug-selling gangs. The current study investigates these hypotheses.

\section{Methods}

\subsection{Target Area}

As described above, the focus of this work is on the neighborhood of Kensington-Fairhill, which is part of the larger Kensington area, located in the northeastern portion of Philadelphia. The area comprises approximately 1.4 square miles, with a population size of nearly 38,000 people ${ }^{2}$, the majority of whom are Puerto Rican ${ }^{3}$ (Friedman et al. 2019). In 2018, concern over rising opioid overdose deaths was the mainspring for the mayor of Philadelphia's executive order declaring a disaster in the neighborhood (Exec. Order No. 3-18 2018). ${ }^{4}$

In addition to rising overdose deaths, as stated earlier, the area also experiences deep structural disadvantage and high violent crime, with approximately double the population below the federal poverty line than for the city as a whole. ${ }^{5}$ The area itself is marred by physical decay as a result of deindustrialization over the past century, which (Friedman et al. 2019) note "represents a perfect

2 This figure is a weighted count using the 2014-2018 ACS 5 year average and areal interpolation procedures described further in this section.

3 From the 2014-2018 ACS 5 year average, 72\% of the total weighted population in the target area are ethnically Hispanic or Latino, and of this group, $78 \%$ are Puerto Rican.

4 https://www.phila.gov/ExecutiveOrders/Executive\%20Orders/eo99318.pdf.

5 According to the 2014-2018 American Community Survey, 54\% of the population in Kensington were below the poverty line, compared to $25 \%$ in the city as a whole. 
environment for harboring difficult-to-police drug markets, sex work, drug consumption shooting galleries, and homeless squats" (p. 7). The authors' recent ethnographic work in the neighborhood documents how structural disadvantage and the ethno-racial makeup of the community positions it to be a hub for the illicit narcotics trade, and consequently, violent crime (Friedman et al. 2019). Spending nearly half a decade in a 10-block area encompassing much of our target area, they found that the ethnic makeup of this neighborhood provides a neutral meeting ground for black and white users to purchase their product without drawing too much attention. Indeed, they found that most of the buyers were not residents themselves, but users coming to the local drug markets from outside the neighborhood.

\subsection{Spatial Unit}

As the focus of our research is on drug trafficking corners, we use Thiessen polygons as our unit of analysis, a network of which is constructed around street corners in the target area of Kensington-Fairhill. A Thiessen polygon is a geometric unit that contains all geographic space closest to its centroid (street corners) than any other polygon's centroid (Chainey and Ratcliffe 2005; Taniguchi et al. 2011). A Thiessen polygon network was used for both theoretical and practical reasons. From a theoretical standpoint, street corners are central hubs of activity for gangs in general and open-air drug markets (Whyte 1955; Topalli et al. 2002; Hsu and Miller 2017). It has long been acknowledged that gangs conduct their day-to-day operations at smaller geographic scales than neighborhoods, Census tracts, or the full extent of their territory (Tita et al. 2005; Valasik and Tita 2018). Commonly called their "set spaces", gangs may choose the places (e.g., street corners) where they hang out and conduct their daily activities, including selling drugs, based on a variety of factors related to the built environment or the relative locations of other gangs' set spaces (Tita et al. 2005; Valasik and Tita 2018). This study echoes prior research that has used Thiessen Polygons as units approximating gang-drug corners within larger set spaces (Taniguchi et al. 2011).

More practically, Thiessen polygons centered around street corners allow for aggregating point data to the nearest corner, reducing potential bias resulting from coding errors (Weisburd et al. 1994). Relatedly, Thiessen polygons are tessellated, ensuring observations are assigned to independent units. Thiessen polygons have been used in previous studies of crime, e.g., (Ratcliffe et al. 2011; Haberman 2017; Piza and Gilchrist 2018). The target area for this analysis was composed of 533 Thiessen polygons, representing approximately $2.5 \%$ of the street corners in the city. For the remainder of the article, we use Thiessen polygons and street corner units interchangeably.

\subsection{Data and Measures}

\subsubsection{Dependent Variable}

The outcome measure of interest for the current study is accidental drug overdose deaths occurring in each Thiessen polygon in the target area. We examined these data for the period between 1 January 2015 and 31 December 2019, with the multivariate analyses focused on the two-year period from 2018 to 2019. Accidental OD incidents were obtained deidentified from the Drug Enforcement Administration (DEA). These data are not restricted to opioid-related deaths. Among other indicators, these data included information on the address of the overdose event location, as well as the death location. Because we are interested in where overdoses are taking place, we focus on the overdose event location, and thus our discussion of OD incidents throughout the paper refers to accidental OD events that took place within the city of Philadelphia, but these events all eventually resulted in a death. We used ArcGIS Pro 2.6.0 software to geocode OD incidents occurring in Philadelphia, resulting in a citywide hit rate of $95 \%$, exceeding commonly-referenced standards (Ratcliffe 2004). ${ }^{6}$ All OD incidents occurring within Kensington-Fairhill were subsequently aggregated to counts per individual Thiessen polygon.

6 Ratcliffe (2004) found that an $85 \%$ hit rate was an acceptable minimum standard when conducting spatial crime analysis, although recent work has returned to this question of minimum acceptable hit rates. Briz-Redón et al. (2020) replicated (Ratcliffe 2004) procedure using five crime types aggregated to five different areal units in Valencia. They found that 
The distribution of OD counts per year from 2015 through 2019 across different race and ethnicity groups is displayed in Table 1 . Though accounting for $2.5 \%$ of the city's street corners, the target area of focus in this study experienced slightly more than 13\% of the city's overdoses between 2015 and 2019. Citywide, overdose deaths increased more than 60\% between 2015 and 2019, while the number of ODs in Kensington-Fairhill increased by 50\%. Drug overdose victims in Philadelphia are primarily white, though the share of non-white victims appears to have grown, both in the city as a whole and in the target area, during the same time period. Between 2015 and 2019, the share of overdose victims who were non-white grew nearly $80 \%$ citywide, and by $375 \%$ in Kensington-Fairhill. The share of Hispanic overdose victims grew more than $120 \%$ and $91 \%$ in the city and Kensington-Fairhill, respectively. Victims who overdosed in Kensington-Fairhill who were from Philadelphia and for whom a home address was known came from many different parts of the city, including neighborhoods in and around the target area, and far north and south of the city. While we do not know the individual socioeconomic status of the OD victims who make up our sample, we found by analyzing the census tracts of their home address that most, but not all, of the decedents hailed from neighborhoods with high levels of concentrated disadvantage ${ }^{7}$. In 2019 alone, most of the victims in the target area for whom a Philadelphia address was known lived in tracts more than 1 standard deviation above the city average in concentrated disadvantage, with some home tracts as high as nearly 2.5 standard deviations above the average.

Table 1. Number of ODs in the Target Area and Citywide, by Year.

\begin{tabular}{|c|c|c|c|c|c|c|c|c|c|c|c|c|}
\hline $\begin{array}{c}\text { Year } \\
\text { Demographics of } \\
\text { OD Victims }\end{array}$ & \multicolumn{2}{|c|}{2015} & \multicolumn{2}{|c|}{2016} & \multicolumn{2}{|c|}{2017} & \multicolumn{2}{|c|}{2018} & \multicolumn{2}{|c|}{2019} & \multicolumn{2}{|c|}{ Total } \\
\hline Total Phila. ODs & 666 & 100.0 & 832 & 100.0 & 1139 & 100.0 & 1021 & 100.0 & 1070 & 100.0 & 4728 & 100.0 \\
\hline \multicolumn{13}{|l|}{ Race } \\
\hline White & 445 & 66.8 & 565 & 67.9 & 817 & 71.7 & 682 & 66.8 & 677 & 63.3 & 3186 & 67.4 \\
\hline \multicolumn{13}{|l|}{ Ethnicity } \\
\hline Hispanic & 77 & 11.6 & 103 & 12.4 & 156 & 13.7 & 137 & 13.4 & 172 & 16.1 & 645 & 13.6 \\
\hline Non-Hispanic & 585 & 87.8 & 721 & 86.7 & 970 & 85.2 & 875 & 85.7 & 858 & 80.2 & 4009 & 84.8 \\
\hline Unknown & 4 & 0.6 & 8 & 1.0 & 13 & 1.1 & 9 & 0.9 & 40 & 3.7 & 74 & 1.6 \\
\hline Unknown & 1 & 1.0 & 0 & 0.0 & 0 & 0.0 & 0 & 0.0 & 0 & 0.0 & 1 & 0.2 \\
\hline \multicolumn{13}{|l|}{ Ethnicity } \\
\hline Hispanic & 34 & 34.0 & 35 & 33.3 & 53 & 33.1 & 41 & 35.7 & 65 & 43.3 & 228 & 36.2 \\
\hline Non-Hispanic & 64 & 64.0 & 66 & 62.9 & 103 & 64.4 & 72 & 62.6 & 75 & 50.0 & 380 & 60.3 \\
\hline Unknown & 2 & 2.0 & 4 & 3.8 & 4 & 2.5 & 2 & 1.7 & 10 & 6.7 & 22 & 3.5 \\
\hline
\end{tabular}

Notes. Total number of accidental overdose deaths occurring within Philadelphia between 2015 and 2019 that could be successfully geocoded (i.e., no missing or unknown event address) or those that did not occur at the Philadelphia International Airport, which was excluded from our citywide network of Thiessen polygons. Overdose data from Drug Enforcement Administration. Phila. refers to Philadelphia. OD refers to Overdose deaths. * Percentages in this row reflect the percentage of overdoses out of the total number of overdoses in the city.

Table 2 displays the distribution of ODs by Thiessen polygons in the study area. ODs are a relatively rare occurrence for most Thiessen polygons in the study area. Nearly $\frac{3}{4}$ of Thiessen polygons experienced 0 or 1 ODs between 2015 and 2019.

the minimum acceptable hit rate varied by the crime type and areal unit under consideration. For all crime types, when considering a spatial extent of 566 Thiessen polygons constructed around street intersections in Valencia, their analyses yielded a minimum acceptable hit rate ranging from $72 \%$ to $83.7 \%$ (Briz-Redón et al. 2020).

7 As detailed in the measurements section, concentrated disadvantage is an index comprising the extent of unemployment, poverty, households receiving public assistance, and female-headed households. 
Table 2. Number of ODs in Thiessen Polygons in the Study Area, 2015-2019.

\begin{tabular}{cccc}
\hline N of ODs & N of TPs & $\mathbf{\%}$ & Cumulative $\%$ \\
\hline 0 & 269 & 50.47 & 50.47 \\
1 & 116 & 21.76 & 72.23 \\
2 & 75 & 14.07 & 86.3 \\
3 & 28 & 5.25 & 91.56 \\
4 & 14 & 2.63 & 94.18 \\
5 & 11 & 2.06 & 96.25 \\
$6-9$ & 14 & 2.63 & 98.87 \\
$10+$ & 6 & 1.13 & 100 \\
Total & 533 & 100 & 100
\end{tabular}

Notes. Overdose data from Drug Enforcement Administration. OD refers to overdose deaths. TP refers to Thiessen polygons.

\subsubsection{Independent Variables}

The primary predictors of interest included indicators of DTO or drug corner status. A dichotomous variable was created indicating whether the street corner was designated a Kensington-Fairhill "priority corner." Priority corners were determined in mid-2018 by a law enforcement working group that was comprised of representatives from state, local and federal law enforcement agencies as those that should be prioritized for collaborative long-term investigation efforts. Violent crime and drug seizure data and street-level knowledge were used to define this list of corners based on each corner's volume of drug sales and level of violence (Roselli 2018).

In addition to the measure of priority corner status, a variable was also included to capture the proximity of each street corner unit to priority corners. This variable was calculated from the straight-line Euclidean distance between the centroid of each Thiessen polygon (the street corner) and all priority corners. Each separate distance was then summed to represent the total distance in miles between each Thiessen polygon and the priority corners. Lower values on this variable indicate a street corner unit is closer to priority corners, whereas high values indicate the opposite. Some studies have used a minimum distance measure between the centroid of a spatial unit and key places such as hospitals or fire departments in predicting overdose deaths, e.g., (Li et al. 2019). Similarly, studies examining the spatial exposure of risky facilities on spatial units have used inverse distance calculations that weight places that are closer more and vice versa for those that are further away, e.g., (Trangenstein et al. 2018). Rather than use an inverse distance calculation, which would differentially weight gang corners based on their distance (Ratcliffe and Taniguchi 2008), we sum all distances using equal weights, as we sought to capture the potential influence of all priority DTOs in the target area on ODs as a measure of the agglomeration economy of drug markets. We also wanted to be inclusive of all priority corners in the target area, as we anticipated a higher density of drug purchasing opportunity would likely coincide with higher numbers of overdose deaths.

\subsubsection{Additional Covariates}

In addition to the priority corner indicators, we included a series of social and structural covariates that we expected to have a theoretical relationship with the location of ODs. The typical contextual factors related to social disorganization theory are the structural constraints that give rise to low social control and cohesion (e.g., economic disadvantage, residential instability, foreign-born population). Factors related to small-area places are informed by the routine activities perspective-those factors that tend to attract and/or generate crime acting as places where motivated offenders come together with potential targets and lack of capable guardians. These covariates are listed in turn below.

The sociodemographic context of the Thiessen polygons was measured by four variables constructed from the 2014-2018 American Community Survey (ACS). We included the percent of the population who were male, as prior research has linked this measure positively with heroin-related emergency services calls ( $\mathrm{Li}$ et al. 2019). We also included three variables capturing the social 
disorganization of the street corners (Shaw and McKay 1942). These include an additive index capturing the concentrated disadvantage of the corner. This variable was comprised of the sum of the $\mathrm{z}$ scores for the percent of the population who are unemployed, below the poverty line, living in female-headed households, and the percentage of households receiving public assistance divided by 4 . Residential instability is also measured as an index, comprised of the sum of the $\mathrm{z}$ scores of the percent of renter-occupied housing units and percentage of households moving in after 2014 divided by 2. To capture population heterogeneity, we created a proxy measure for foreign born, operationalized as the percentage of the population who spoke a language at home other than English. ${ }^{8}$

In addition to the social context of street corner units, we include a series of measures related to the environmental context of each unit, as prior research points to the importance of certain environmental covariates in overdose deaths (Hembree et al. 2005; Li et al. 2019). Environmental features of street corner units included the presence of commercial or recreational establishments (Li et al. 2019; Hsu and Miller 2017), proximity of a street corner unit to a park (Groff and McCord 2012; Hsu and Miller 2017; Li et al. 2019), as well as the number of street trees (Wheeler 2018) and presence of bridges as measures of visibility. Commercial land-use data at the parcel level were obtained via the City's open data portal. The land-use data were available as a polygon shapefile that was imported into ArcGIS Pro and overlaid with the Thiessen polygon network to calculate the percentage of commercial or recreational establishments in each street corner unit. Park locations were also obtained via the City's data portal as a polygon shapefile that was overlaid with the Thiessen polygon network. If a Thiessen polygon touched a park, it was given a value of one for the park variable, and a zero if it did not. The number of street trees and presence of bridges were obtained as geocoded point data from the same open data portal. The street trees were measured as part of a 2016 street tree inventory, where each data point represents a tree. The number of trees was summed for each Thiessen polygon. Considering bridge presence, a Thiessen polygon was said to contain a bridge if it contained a bridge point after overlaying the point dataset with the Thiessen polygon network. We expected the measure of whether the Thiessen polygon contained a bridge would be particularly relevant to ODs, since Kensington has a recent history with homeless encampments situated beneath bridges and overpasses (Metraux et al. 2019). Many of the inhabitants of these encampments are opioid users.

Regarding drug markets more generally, past research and the routine activities perspective would suggest that environmental features that maximize retail accessibility and security confer more success to drug dealing, or otherwise play into dealers' decisions on where to do business (Eck 1995; St. Jean 2007; Barnum et al. 2017; Bernasco and Jacques 2015). For instance, Valasik (2018) used Risk Terrain Modelling (RTM) of 22 different environmental risk factors to predict gang assault and homicide. He found that proximity to a Metro rail stop was one of the strongest predictors of gang assault. In part, he notes this may be due to the routine activities of gang members themselves, who, along with other community residents, often congregated around transit stops awaiting travel into the city. Measures intending to capture the accessibility of street corners were thus included in this study, as we hypothesized that corners conducive both to higher flows of people and drug sales would be associated with more ODs. One measure included a dichotomous indicator of whether the Thiessen polygon contained any transit stops (bus, train, trolley, or subway). Data on transit stop locations were obtained via the Southeastern Pennsylvania Transit Authority's (SEPTA) open data portal ${ }^{9}$. The number of street segments intersecting with each Thiessen polygon was also included. This variable was constructed by overlaying a Philadelphia streets file with the Thiessen polygon layer in ArcGIS Pro, and capturing the number of street segments that intersected with each polygon. Whether Thiessen polygons contained any streets designated as "No-thru trucks streets" was included as another measure of accessibility, given these would be smaller, local streets more conducive to pedestrian flow. Both street measures were sourced from the city of Philadelphia's open data web portal.

8 This American Community Survey item was not available at the Census block group level.

9 http://septaopendata-septa.opendata.arcgis.com/. 
Finally, we use 311 calls for service occurring between 1 January 2018 and 31 December 2019 as measures of physical incivilities and informal social control. We obtained geocoded data on five categories of quality of life calls from the Philly 311 department. These data are also available via the City's open data web portal ${ }^{10}$. The categories of calls included graffiti removal, streetlight outages, vacant house calls, vacant lot cleanups, and calls regarding abandoned vehicles.

\subsection{Allocation of Census Data to Thiessen Polygons}

Thiessen polygons require an additional step compared to more traditional census geographies when aggregating census data to each unit. Thiessen polygons may fall within multiple census units, such as census block groups (CBGs). A simple method of assignment would be to assign each Thiessen polygon the census attributes of the CBG that its centroid fell within. However, in this research, we follow Taniguchi, Ratcliffe, and Taylor (2011) in proportionally allocating census attributes to Thiessen polygons. This method calculates the proportion of area in CBGs that make up each Thiessen polygon, and uses this proportion to allocate the count data to each Thiessen polygon. For instance, if 25\% of CBG 100 and 50\% of CBG 101 fall within Thiessen polygon A, the weighted population for Thiessen polygon A would be calculated as:

$$
\text { Pop }_{\mathrm{TPA}}=0.25^{*} \operatorname{Pop}_{\mathrm{CBG} 100}+0.50 * \mathrm{Pop}_{\mathrm{CBG} 101}
$$

All census attributes were proportionally allocated to Thiessen polygons using this method. Census measures used in the analyses, including the percentage male, speaking a foreign language at home, concentrated disadvantage and residential instability indices, were calculated from these weighted counts. Table 3 presents descriptive statistics of all measures included in the analyses. ${ }^{11}$

Table 3. Descriptive Statistics.

\begin{tabular}{lcccccc}
\hline Variable & Mean & SD & Min & Max & Skew & N \\
\hline Accidental overdose deaths, 2018-2019 & 0.5 & 0.9 & 0 & 6 & 2.47 & 533 \\
Priority corner & 0.03 & 0.18 & 0 & 1 & 5.16 & 533 \\
Proximity to all priority corners & 13.53 & 2.68 & 9.77 & 22.18 & 0.74 & 533 \\
Concentrated disadvantage & 0.84 & 0.52 & -0.55 & 2.97 & 0.42 & 533 \\
Residential stability & 0.17 & 0.67 & -1.87 & 2.02 & 0.24 & 533 \\
Foreign language at home & 1 & 0.5 & -0.15 & 4.74 & 2.05 & 533 \\
Transit stops & 0.13 & 0.34 & 0 & 1 & 2.16 & 533 \\
No truck street & 0.26 & 0.44 & 0 & 1 & 1.07 & 533 \\
Number of street segments & 3.83 & 0.61 & 2 & 6 & 0.21 & 533 \\
Number of trees & 2.62 & 3.76 & 0 & 33 & 2.9 & 533 \\
Presence of a park & 0.1 & 0.3 & 0 & 1 & 2.68 & 533 \\
Presence of a bridge & 0.08 & 0.28 & 0 & 1 & 2.99 & 533 \\
Calls for abandoned vehicles & 2.65 & 3.47 & 0 & 27 & 2.71 & 533 \\
Calls for graffiti & 4.92 & 9.28 & 0 & 87 & 4.62 & 533 \\
Calls for broken street light & 0.87 & 1.35 & 0 & 9 & 2.48 & 533 \\
Calls for vacant houses & 1.73 & 3.31 & 0 & 27 & 3.23 & 533 \\
Calls for vacant lot & 1.5 & 2.93 & 0 & 24 & 3.71 & 533 \\
Male & 49.05 & 6.78 & 27.93 & 82.52 & 0.04 & 533 \\
Area (square ft) & $73,478.49$ & $34,305.69$ & $20,439.41$ & $312,922.9$ & 2.37 & 533 \\
\hline
\end{tabular}

Notes. SD refers to standard deviation, square ft refers to square feet.

10 https://www.opendataphilly.org/.

11 The land use variable measuring the percent commercial or recreational land use was dropped from all analyses due to its correlation with transit stops, impeding model convergence. We retained the transit stops variable as we expected it would vary across the spatial units in our study more than the land use variable, particularly due to the very small size of the units. 


\subsection{Spatial Concentration of ODs}

Before multivariate analyses were conducted, we used a novel metric, the Rare Event Concentration Coefficient (RECC), to determine the concentration of accidental ODs throughout the study area between 2015 and 2019 (Curiel and Bishop 2016; Curiel et al. 2018). We examined the RECC annually to provide insight into the stability (or instability) of the concentration of ODs over time, which in turn, guided which years of data were aggregated for the predictive analyses. The RECC was conceived as a concentration metric designed for rare events (e.g., crime, volcano eruptions, and traffic accidents) that typically follow a Poisson-type process. The rarity at which ODs occurred in the target area necessitated this approach as most street corner units experienced 0 ODs across the five years of this study. Because whether a place experiences 0 events in a year does not mean its probability of experiencing crime is equal to 0 (Curiel et al. 2018), it is more desirable to consider observed counts as realizations of an underlying Poisson process, rather than focus on the counts themselves (Curiel and Bishop 2016).

The calculation of the RECC proceeded in two main steps. The first was to create a distribution of expected rates at which ODs occur. This was accomplished by estimating a mixture model of the observed counts of ODs for all Thiessen polygons. We used the CAMAN package in $\mathrm{R}^{12}$ for this analysis. This process identified groups of Thiessen polygons with the same rate of OD occurrence in each year. A vector of the rates was then created, where the frequency at which each rate appeared in the vector was proportional to the number of Thiessen polygons that fell into its respective group. The second step in the calculation was to apply the formula for the Gini coefficient to the vector of expected rates, which produced the RECC. The RECC takes on a value between 0 and 1 , and is interpreted in the same manner as the Gini coefficient, with values closer to 0 denoting more equality (or more dispersion), and values closer to 1 indicating more concentration. We repeated this analysis for ODs in Thiessen polygons for each year between 2015 and 2019. The resulting values are in Table 4. The RECC dropped by nearly 20\% between 2015 and 2019, reflecting that ODs are more dispersed-that is, they are more evenly experienced by street corner units in Kensington-in the latter part of the time period.

Table 4. Rare Event Concentration Coefficient (RECC) for Overdose Deaths in the Target Area, 2015-2019.

\begin{tabular}{ccc}
\hline Year & RECC-Rates & RECC-Raw \\
\hline 2015 & 0.71 & 0.711 \\
2016 & 0.615 & 0.618 \\
2017 & 0.649 & 0.651 \\
2018 & 0.451 & 0.453 \\
2019 & 0.568 & 0.571 \\
\hline
\end{tabular}

Notes. RECC refers to Rare Event Concentration Coefficient. Values in the "RECC-Rates" column were calculated using the natural log of the area of the Thiessen polygons as an offset in the mixture model. The "RECC—Raw" column does not use an offset in the mixture model; the estimated group rates are estimated counts per year.

\subsection{Analytic Approach Predicting Counts of ODs in Thiessen Polygons}

The RECC analyses revealed a shift in the spatial dispersion of ODs in 2018 and 2019, suggesting ODs are less concentrated in more recent years. We therefore focused our multivariate analyses predicting counts of ODs in street corner units on those overdose deaths occurring in 2018 and 2019. A global Moran's I test of the 2018 and 2019 ODs also revealed significant positive spatial autocorrelation among the target area Thiessen polygons (Moran's $I=0.24$, pseudo- $p<0.001$ ) (Anselin 1996). This motivated our use of a spatial econometric method using an information theoretic approach to estimating ODs in Thiessen polygons. Specifically, we employed a series of generalized cross-entropy (GCE) models, which are well suited for examining rare count outcomes with a correlated

12 https://cran.r-project.org/web/packages/CAMAN/CAMAN.pdf. 
spatial structure. GCE models are also adept at handling both over- and underdispersion and have been demonstrated as more suitable (compared to negative binomial regression) to estimating spatially autocorrelated and overdispersed count outcomes through simulations (Bhati 2008). The GCE modeling approach has been used in previous place-based crime studies, including those examining homicides in Chicago (Bhati 2008) and the effect of alcohol outlets on violence and disorder in Washington, DC (Roman et al. 2008; Roman and Reid 2012). It is important to note that earlier studies comparing GCE model outcomes to outcomes from the more typical negative binomial regression models incorporating a spatial lag variable reveal the superiority of the GCE models for handling the spatial structure of the data (Roman et al. 2008). We used a GCE macro written for the SAS platform to execute all regression models (see Roman et al. 2008).

The general model building strategy we follow was nested according to different theoretical blocks of interest. The first model predicted the number of ODs including only the key gang variables, controlling for the percentage of the population who are male. The second model incorporated the variables measuring the social structural features of the street corners, including measures of social disorganization. Model three examined the effect of certain environmental features of street corners on drug overdoses. Finally, model four explored the effect of the priority corner status on ODs, while simultaneously considering the social and environmental features of the street corners. For each model considered, the natural log of the area of each Thiessen polygon in feet was used as the offset variable.

\section{Results}

The GCE regression results from all four models are detailed in Table 5. Unlike OLS regression models, the coefficients yielded from the GCE models do not allow for a direct substantive interpretation (Bhati 2008). However, marginal effects can be calculated from the GCE coefficients, which can be interpreted as the change in the expected rate of ODs per square foot given a one-unit change in the predictor. In order to save space, the marginal effects are not shown in Table 5, but they are noted in the text and available from the lead author upon request. In Model 1, both the gang corner status and the proximity to gang measure were significantly related to the rate of OD incidents in each street corner, controlling for the percentage male population. The priority corner status was positively related to ODs, indicating that corners that were prioritized for drug gang enforcement efforts were associated with higher rates of ODs than those that were not. The variable capturing each corner's proximity to all gangs was negatively related to ODs, meaning that the less distance between a street corner and all gang corners in the target area, the higher the OD rate that corner is expected to have. However, the pseudo- $\mathrm{R}^{2}$ for this model was -0.09 , indicating a very poor fit to the data. Model 2 incorporated three measures of social disorganization of the street corners. The gang status of the corner remained a positive and significant indicator of ODs, however the measure capturing the proximity to all gang corners was no longer significant once considering the social disorganization of the corners. Consistent with expectations, both concentrated disadvantage and residential instability were significantly, and positively related to the rate of ODs. Yet, the measure of foreign language at home was significantly and negatively related to overdoses. The Model 2 pseudo- $\mathrm{R}^{2}$ was 0.04 , indicating Model 2 was also a poor fit.

Model 3 incorporated aspects of the physical environment of the corners into the model, resulting in an improved model pseudo- $\mathrm{R}^{2}$ of 0.12 . Both priority corner predictors dropped out as significant predictors of ODs when simultaneously controlling for social disorganization and certain environmental characteristics of the corners. The coefficients for all three social disorganization factors remained largely unchanged from Model 2, yet there were only two environmental characteristics-transit stops and the number of street segments-that were significantly associated with ODs. 
Table 5. GCE Model Results.

\begin{tabular}{|c|c|c|c|c|c|c|c|c|}
\hline \multirow{2}{*}{$\begin{array}{l}\text { Predicting Overdose Deaths } \\
\text { Variable }\end{array}$} & \multicolumn{2}{|c|}{ Model 1} & \multicolumn{2}{|c|}{ Model 2} & \multicolumn{2}{|c|}{ Model 3} & \multicolumn{2}{|c|}{ Model 4} \\
\hline & Coeff. & S.E. & Coeff. & S.E. & Coeff. & S.E. & Coeff. & S.E. \\
\hline Constant & $4.103^{* * *}$ & 0.743 & $3.126^{* *}$ & 1.123 & -0.279 & 0.344 & $-13.625^{* * *}$ & 2.815 \\
\hline \multicolumn{9}{|l|}{ Drug Trafficking Organizations/Gangs } \\
\hline Priority corner & 0.406 * & 0.184 & $0.446^{* *}$ & 0.183 & 0.215 & 0.214 & $0.479 *$ & 0.233 \\
\hline Proximity to all priority corners & $-0.042 * * *$ & 0.011 & -0.020 & 0.013 & -0.031 & 0.019 & $-0.092^{* * *}$ & 0.03 \\
\hline \multicolumn{9}{|l|}{ Social Disorganization } \\
\hline Concentrated disadvantage & - & - & $0.254^{* * *}$ & 0.082 & $0.246^{* * *}$ & 0.085 & $0.397^{* * *}$ & 0.132 \\
\hline Residential stability & - & - & $0.155 *$ & 0.064 & $0.158 *$ & 0.07 & 0.108 & 0.099 \\
\hline Foreign language at home & - & - & $-0.448^{* * *}$ & 0.094 & $-0.393^{* * *}$ & 0.103 & $-0.463^{* * *}$ & 0.143 \\
\hline \multicolumn{9}{|l|}{ Physical Environment } \\
\hline Transit stops & - & - & - & - & $0.396^{* * *}$ & 0.114 & $0.624^{* * *}$ & 0.156 \\
\hline No truck street & - & - & - & - & 0.009 & 0.118 & 0.038 & 0.145 \\
\hline Number of street segments & - & - & - & - & $0.257^{* * *}$ & 0.078 & 0.190 * & 0.096 \\
\hline Number of trees & - & - & - & - & -0.029 & 0.017 & 0.015 & 0.02 \\
\hline Presence of a park & - & - & - & - & -0.187 & 0.203 & $-0.590^{* *}$ & 0.239 \\
\hline Presence of a bridge & - & - & - & - & 0.189 & 0.142 & $0.457^{* *}$ & 0.182 \\
\hline \multicolumn{9}{|l|}{ Informal Social Control/Incivilities } \\
\hline Calls for abandoned vehicles & - & - & - & - & - & - & $-0.047^{*}$ & 0.023 \\
\hline Calls for graffiti & - & - & - & - & - & - & -0.005 & 0.007 \\
\hline Calls for broken street light & - & - & - & - & - & - & -0.056 & 0.044 \\
\hline Calls for vacant houses & - & - & - & - & - & - & $0.055^{* * *}$ & 0.015 \\
\hline Calls for vacant lot & - & - & - & - & - & - & $0.042 * *$ & 0.016 \\
\hline \multicolumn{9}{|l|}{ Control } \\
\hline Male & $-0.013 *$ & 0.007 & -0.003 & 0.007 & -0.003 & 0.002 & 0.011 & 0.01 \\
\hline Pseudo R2 & & -0.09 & & 0.04 & & 0.12 & & 0.22 \\
\hline Rho & & $1.23^{* * *}$ & & $1.20 * * *$ & & $1.00 * * *$ & & -0.08 \\
\hline Overdispersion parameter & & $0.80^{* * *}$ & & $0.81^{* * *}$ & & $0.75^{* * *}$ & & $0.57^{* * *}$ \\
\hline
\end{tabular}

Notes. GCE refers to Generalized Cross Entropy. Coeff. refers to coefficient, S.E. refers to standard error. ${ }^{*} p<=0.05^{* * *} p<=0.01 ; * * * p<=0.001$. 
The full model (Model 4) included both priority corner variables, and social and environmental features of the street corners in predicting rates of ODs. The pseudo- $\mathrm{R}^{2}$ for the main model increased to 0.22 , signifying an improvement in model fit. Taking into account the features of the social and built environment, the variable capturing priority corner status significantly predicted overdose deaths, in that street corners that are designated drug trafficking corners were associated with 0.42 more expected overdoses per square foot. Similarly, the measure that captures the proximity to all priority corners was significant and negative, meaning the closer a street corner is to all drug trafficking corners, the higher the expected rate of ODs is in that corner, net of all other covariates. Stated differently, each one-mile increase in the distance to all priority corners was associated with an expected 0.08 fewer ODs per square foot.

With regard to the social disorganization factors, the final model revealed a significant relationship between concentrated disadvantage and ODs (marginal effect $=0.34$ ) and the percent speaking a foreign language at home and ODs (marginal effect $=-0.40$ ). Additional contextual influences include the positive and significant effects of transit stops and number of intersecting street segments, measures intending to capture the accessibility of the street corner, on overdose deaths. Consistent with our expectation, the results suggest street corners that generate more pedestrian flow were more likely to have a higher expected rate of overdose deaths (transit stops: marginal effect $=0.54$, number of street segments: marginal effect $=0.16$ ). Whether a street corner had a transit stop in particular was associated with an expected increase of 0.54 ODs per square foot. However, the flag for whether a street corner unit touched a park was significant and negatively related to overdose deaths (marginal effect $=-0.51$ ). Finally, measures capturing the informal social control and incivilities of the area, calls for vacant houses and for vacant lots, were significantly and positively associated with overdose deaths (marginal effects $=0.05,0.04$, respectively). Calls for abandoned vehicles were also significantly associated with more ODs, yet in the opposite direction (marginal effect $=-0.04$ ). Importantly, Rho, the coefficient representing the spatial autocorrelation, was significant and positive for Models 1-3, yet the full model had a non-significant Rho.

\section{Limitations}

Before we discuss the findings, there are several limitations to this study that require mention. The statistical analyses we employed are inherently cross-sectional, and hence, our findings can only comment on the correlational relationship between our predictors of interest and overdose deaths. Future work could employ longitudinal methods to establish a causal link between presence of gang-controlled drug corners and overdose deaths that might result. Second, our indicator for whether a Thiessen polygon contained a priority drug trafficking corner status is not inclusive of all gang-related corners in the target area (or even all drug-selling gang corners), though it captures the most violent and/or high-volume drug trafficking corners as of 2018. Third, our data preclude our ability to know whether or not ODs are affiliated with a given drug trafficking corner. The target area is relatively small, with some drug-selling gang corners in relatively close proximity. If individuals use drugs nearby after they purchase them, it is possible that they OD in another gang's drug sales territory. Finally, although the RECC analyses showed that the dispersion of overdose deaths changed over time, we did not run analyses that might have given us clues as to why the concentration changed over time. We could hypothesize that these changes had to do with macro-level forces such as the steep increase in sales of fentanyl that occurred throughout the US (and Philadelphia) temporally around late 2016 and 2017, or the closing of a large outdoor homeless encampment supporting users of heroin around the same time, but we do not have the appropriate data to validly model these changes. These limitations notwithstanding, this study helps shed light on the connection between drug trafficking gangs and the spatial location of accidental overdose deaths. 


\section{Discussion and Conclusions}

Using multiple methods, this work sought to answer whether deaths from accidental drug overdose are located in close proximity to gang-controlled street corners in an area of a city known for its agglomeration economy drug markets and provide insight into which features of places are associated with the location of overdose deaths using theory as a guide. Findings from RECC analyses indicated that patterns of overdose mortality clustering changed over time, providing guidance that predictive analyses should focus only on a two-year period where the spatial patterns were similar, as opposed to a longer time period. As stated in the "limitations section", OD dispersion could potentially be attributed to different factors changing the routine activities of drug users in the neighborhood attributed to changes in access to public spaces such as the 2017 cleanup of a large, open-air heroin camp at the Conrail train tracks in Kensington (Wolfram 2017)_potentially displacing many homeless heroin users. It could be that this displacement shifted many users' routine activities and in consequence shifted the distribution of ODs across Kensington. It may also suggest that risky environments move around and change with the habits of individuals. A state level policy change may also have influenced the dispersal of overdose deaths in Kensington during the time period examined. The governor of Pennsylvania issued a standing order in 2015 allowing for all citizens-not just emergency services personnel-to obtain the overdose-reversal medication Naloxone (Schwartz et al. 2020). This change allows for more people, including drug users and sellers, to carry and administer the medication (Feldman 2020).

The GCE models revealed that street corners controlled by drug trafficking gangs or those that are situated centrally for easy access to multiple drug corners were associated with more ODs, echoing previous work finding a significant positive influence of gang member density at the block level and the presence of a drug house at the parcel level on overdose deaths (Headley Konkel and Hoffman 2020). The results also suggest drug market dynamics where buyers use drugs right away or close to purchase, consistent with anecdotal evidence from law enforcement. Unsurprisingly, street corners that were designated as priority corners showed clear evidence of being affiliated with a higher rate of ODs. Further, indeed, additional analyses (not shown) revealed that the average number of ODs in Thiessen polygons designated as priority corners was double that of non-gang corners ${ }^{13}$. A key implication to also note from these findings is that the actual location and status of individual drug corners are not the only measures predicting higher counts of overdose deaths. The agglomeration economy of the Kensington-Fairhill drug market appears to contribute to its overall retail success, but also its experience with overdose deaths. The significance of the variable capturing the proximity to gang-controlled drug corners leads us to believe that even corners that are not gang-controlled may experience more ODs because of where they are relatively located in space. There were 54 Thiessen polygons in the top 90th percentile in proximity to drug corners, yet the average count of ODs for this group was $8 \%$ higher than for the target area polygons as a whole. Geographically, these polygons were clustered in the lower middle of the target area, several blocks from the Kensington Avenue corridor. Our analyses reveal that it is important to capture not only the DTO status of corners in predicting the spatial location of ODs, but also where each street corner is situated within the wider network of open-air drug market corners.

We also found support for social disorganization theory with regard to the relevance of certain macro structural constraints in predicting overdose deaths. Our findings revealed a significant effect of concentrated disadvantage on ODs, which is somewhat inconsistent with previous work. For instance, Martinez et al. (2008) and Li et al. (2019) both included structural deprivation measures in their models predicting overdoses, yet the effects were non-significant. The differences in findings here could relate

13 There were 18 Thiessen polygons designated as priority corners, experiencing 19 ODs in 2018-2019. This resulted in a mean of 1.06 ODs per Thiessen polygon. There were 515 Thiessen polygons that were not designated as priority corners, experiencing 246 ODs in 2018-2019, with a mean of 0.48 ODs per Thiessen polygon. 
to the different unit of analyses used or that there are regional differences (across the US) with regard to how social disorganization influences drug misuse/overdose mortality. The negative effect of our measure to capture foreign born—the percent speaking a foreign language at home-on ODs in our model, however, echoes the (Martinez et al. 2008) finding that racial heterogeneity had a negative relationship with drug overdoses. While it is impossible to know the precise mechanism responsible for this relationship, it could be that our measure of foreign born reflects a type of protective factor that has been associated with concentrations of immigrants and crime (Ousey and Kubrin 2018). For our study, the Census-based measures represent the residents living in homes in the street corner areas, not the characteristics of the overdose victims. Similar to Johnson and Shreve (2020), we are unable to account for individual characteristics of the decedents due to the aggregate nature of our analyses and idiosyncrasies of the data used here. Specifically, while the data often contained the home address of decedents (some were labeled missing, unknown, or homeless), there may be some question as to the reliability of this indicator in practice, particularly given the transience of much of the drug using population in Kensington. This fact notwithstanding, we found that $34 \%$ of the fatal OD victims in the target area for the period 2018-2019 were described as dying at their residence. ${ }^{14}$ From this we can cautiously surmise that in at least $1 / 3$ of the OD cases in the study area, for the social disorganization measures, the corner attributes partially reflect the macro-level structural characteristics related to the decedents' themselves. This makeup agrees with recent qualitative work in Kensington that finds most drug users in the neighborhood are coming in from other places (Friedman et al. 2019). Future research could not only explore how the individual-level characteristics of those misusing drugs in micro-places interact with characteristics of residents in those neighborhoods, but also the dynamics of drug use and overdose among different populations - residents from inside and outside of the neighborhood and the homeless population-in and around this drug market.

We also found that the accessibility of the street corners themselves translated to more ODs. This is contrary to Li et al. (2019) finding that public transportation (measured as bus coverage) was not significantly related to overdose deaths. The significant negative relationship between street corners that touched a park and overdose deaths was also contradictory to Li et al. (2019) findings of a positive relationship between these two constructs, though their measure of park presence differed from ours in that it captured the proportion of park area in each census block group. For the measures capturing the informal social control and incivilities of the area, two call types, those for vacant houses and those for vacant lots, were significantly and positively associated with overdose deaths, while calls for abandoned vehicles were significantly and negatively associated with ODs. We are unaware of previous work examining these specific call types on overdose deaths, but research examining the degradation of the built environment has found mixed results with regard to its effects on overdose deaths. For example, (Hembree et al. 2005) found that the percentage of acceptably clean streets in New York City was a negative predictor of drug overdose deaths, while (Cerdá et al. 2013), also looking at New York City, found that acceptably clean sidewalks were only a significant predictor when comparing analgesic-related ODs with heroin-related ODs, but not compared with non-overdose accidental deaths. Furthermore, the authors found that dilapidated housing was not a significant predictor for analgesic-related ODs for either comparison. In the context of our results, more calls regarding vacant houses or lots could be related to the actual presence of such vacant lots and houses; spaces that may be attractive for illicit drug use.

Ultimately, the results from our GCE models and RECC analyses have multiple implications for policy related to community overdose mortality and gangs actively involved in selling heroin. Our findings suggest programs seeking to address ODs should be mobile and targeted specifically to risky places to enhance service reach. The emphasis here is on micro-places-prevention efforts can be

14 i.e., the death location was noted as "residence", and the decedents' home address, event address, and death address were all the same. 
pinpointed with precise targeting-down to blocks and corners. Mobile outreach initiatives, such as those providing clean syringe exchange or treatment, and other flexible strategies would be a relevant approach to reducing ODs, capable of adapting with the routine activities of users. Particularly in the context of Kensington, where most users are not residents of the neighborhood (Friedman et al. 2019) and therefore may not maintain a static presence or activity space (Brantingham and Brantingham 1995). The effect of priority corner proximity, as well as of accessibility of street corners on ODs, bolsters this idea that locating social service provision and outreach central to drug markets and high traffic locations may prove beneficial.

The co-location of ODs and drug trafficking corners also alludes to the utility of coordinating law enforcement and social services to address both challenges. It has long been acknowledged that "focused, partnership-type law enforcement interventions are generally far more effective responses to ongoing crime problems than are unfocused efforts relying entirely on law enforcement resources" (Mazerolle et al. 2007, p. 116). Coordinated interventions have the potential to disrupt the harm caused by gang members through large-scale drug distribution and gun violence, while attempting to reverse some of the physical and social incivilities brought on certain neighborhood corners that affect residents' quality of life. Indeed, in their systematic review of drug law enforcement, (Mazerolle et al. 2007) found that proactive strategies involving partnerships between law enforcement and third parties or community agencies were the most effective at reducing drug and other crime, as well as increasing community residents' reported quality of life (Mazerolle et al. 2007).

In some jurisdictions, the scale of the current opioid epidemic appears to be facilitating a shift towards increased collaboration between federal, state, and local law enforcement agencies and their public health and social service counterparts to reduce the harm affiliated with drug markets and gangs (Police Executive Research Forum 2016). Collaborative partnerships that include permanent supportive housing would be especially salient for neighborhoods such as Kensington with a recent history of homeless and heroin encampments. So too would strategies that incorporate elimination of or reduction in housing blight. In severely disadvantaged areas such as Kensington-Fairhill, collaborative strategies could benefit from careful, data-driven targeting of micro-locations for clean-up and housing investment following (or simultaneous to) law enforcement strategies for arrest and prosecution. In short, a multipronged strategy of combating drug trafficking organizations while alleviating some of the social and environmental obstacles faced by some areas may go a long way in lessening the impact of individual drug corners and the larger market on overdose deaths. While the current research focused on a single phenomenon, accidental overdose deaths, the scope of the harm brought by drug trafficking organizations on the communities in which they operate is difficult to overstate. Researchers and practitioners should continue to use data to better inform how drug trafficking organizations shape public safety and public health in communities, and in turn, inform innovative solutions to address both.

Author Contributions: Conceptualization, C.G.R., N.J.J., C.H., L.H.; methodology, C.G.R., N.J.J.; formal analysis, C.G.R., N.J.J.; writing-original draft preparation, N.J.J, C.G.R., A.K.M., C.H..; writing-review and editing and substantive additions, N.J.J, C.G.R., A.K.M., C.H.., M.F., L.H.; funding acquisition, C.G.R. All authors have read and agreed to the published version of the manuscript.

Funding: This research was funded under the U.S. Department of Justice, Bureau of Justice Assistance, grant number 2019-AR-BX-0022. Opinions or points of view expressed are those of the authors and do not necessarily reflect the official position/policies of the U.S. Department of Justice.

Acknowledgments: A number of people and agencies provided us with data or assisted when questions arose about particular data elements. Those we thank include Evangelia Manos of Philadelphia's Managing Director's Office, Vito Roselli, Federal Bureau of Investigation, Kendra Viner from the Philadelphia Department of Public Health, Angela Ruffin and staff from the Philly311 office. We also express our gratitude to Nehemiah Haigler at the OAG, and Avinash Bhati and Rafael Prieto Curiel for their statistical advice.

Conflicts of Interest: The authors declare no conflict of interest. 


\section{References}

Anselin, Luc. 1996. The Moran scatterplot as an ESDA tool to assess local instability in spatial. Spatial Analytical 4: 111.

Armenian, Patil, Kathy T. Vo, Jill Barr-Walker, and Kara L. Lynch. 2018. Fentanyl, fentanyl analogs and novel synthetic opioids: A comprehensive review. Neuropharmacology 134: 121-32. [CrossRef]

Barnum, Jeremy D., Walter L. Campbell, Sarah Trocchio, Joel M. Caplan, and Leslie W. Kennedy. 2017. Examining the environmental characteristics of drug dealing locations. Crime E Delinquency 63: 1731-56. [CrossRef]

Bates, Savannah, Vasiliy Leonenko, James Rineer, and Georgiy Bobashev. 2019. Using synthetic populations to understand geospatial patterns in opioid related overdose and predicted opioid misuse. Computational and Mathematical Organization Theory 25: 36-47. [CrossRef]

Bernasco, Wim, and Scott Jacques. 2015. Where do dealers solicit customers and sell them drugs? A micro-level multiple method study. Journal of Contemporary Criminal Justice 31: 376-408. [CrossRef]

Bhati, Avinash S. 2008. A generalized cross-entropy approach for modeling spatially correlated counts. Econometric Reviews 27: 574-95. [CrossRef]

Brantingham, Patricia L., and Paul J. Brantingham. 1981. Notes on the Geometry of Crime. In Environmental Criminology. Edited by Paul J. Brantingham and Patricia L. Brantingham. Beverly Hills: Sage Publications, pp. 27-54.

Brantingham, Patricia L., and Paul J. Brantingham. 1995. Criminality of place. European Journal on Criminal Policy and Research 3: 5-26. [CrossRef]

Briz-Redón, Alvaro, Francisco Martinez-Ruiz, and Francisco Montes. 2020. Reestimating a minimum acceptable geocoding hit rate for conducting a spatial analysis. International Journal of Geographical Information Science 34: 1283-305. [CrossRef]

Bursik, Robert J., and Harold G. Grasmick. 1993. Neighborhoods and Crime: The Dimensions of Effective Community Control. New York: Macmillan.

Carter, Jeremy G., George Mohler, and Bradley Ray. 2019. Spatial concentration of opioid overdose deaths in Indianapolis: An application of the law of crime concentration at place to a public health epidemic. Journal of Contemporary Criminal Justice 35: 161-85. [CrossRef]

CDC (Centers for Disease Control, National Center for Health Statistics). 2020. Wide-Ranging Online Data for Epidemiologic Research (WONDER). Available online: http://wonder.cdc.gov (accessed on 29 September 2020).

Cerdá, Magdalena, Yusuf Ransome, Katherine M. Keyes, Karestan C. Koenen, Kenneth Tardiff, David Vlahov, and Sandro Galea. 2013. Revisiting the role of the urban environment in substance use: The case of analgesic overdose fatalities. American Journal of Public Health 103: 2252-60. [CrossRef]

Chainey, Spencer, and Jerry H. Ratcliffe. 2005. GIS and Crime Mapping. Hoboken: John Wiley and Sons.

Cohen, Lawrence, and Marcus Felson. 1979. Social change and crime rate trends: A routine activity approach. American Sociological Review 44: 588-608. [CrossRef]

Confair, Amy, Amy Carroll-Scott, Katherine Castro, Yuzhe Zhao, Steven Melly, Jennifer Kolker, Stephen Lankenau, and Alexis Roth. 2019. Community Health Profile: Kensington. Philadelphia: Drexel University Urban Health Collaborative.

Connell, Christian M., Tamika D. Gilreath, Will M. Aklin, and Robert A. Brex. 2010. Social-ecological influences on patterns of substance use among non-metropolitan high school students. American Journal of Community Psychology 45: 36-48. [CrossRef]

Curiel, Rafael P., and Steven Bishop. 2016. A measure of the concentration of rare events. Scientific Reports 6: 32369. [CrossRef]

Curiel, Rafael P., Sofia C. Delmar, and Steven R. Bishop. 2018. Measuring the distribution of crime and its concentration. Journal of Quantitative Criminology 34: 775-803. [CrossRef]

DEA (Drug Enforcement Administration \& the University of Pittsburgh). 2018. The Opioid Threat in Pennsylvania. Joint Intelligence Report. DEA-PHL-DIR-036-18. Available online: https://www.dea.gov/sites/default/files/2 018-10/Opioid\%20threat\%20in\%20Pennsylvania\%20FINAL.pdf (accessed on 29 September 2020).

DEA (Drug Enforcement Administration). 2019. National Drug Threat Assessment. DEA-DCT-DIR-007-20. Available online: https://www.dea.gov/sites/default/files/2020-01/2019-NDTA-final-01-14-2020_Low_WebDIR-007-20_2019.pdf (accessed on 29 September 2020). 
Eck, John E. 1995. A general model of the geography of illicit retail marketplaces. Crime and Place 4: 67-93.

Exec. Order No. 3-18. 2018 October 3. Available online: https://www.phila.gov/ExecutiveOrders/Executive\%20Or ders/eo99318.pdf (accessed on 5 November 2020).

Feldman, Nina. 2020. One Woman's Mission to Make Sure Everyone Carries Narcan-Including Drug Dealers. WHYY. July 10. Available online: https://whyy.org/segments/one-womans-mission-to-make-sure-everyone -carries-narcan-including-drug-dealers/ (accessed on 29 September 2020).

Felson, Marcus. 1987. Routine activities and crime prevention in the developing metropolis. Criminology 25: 911-31. [CrossRef]

Felson, Marcus. 1994. Crime and Everyday Life: Insight and Implications for Society. Thousand Oaks: Pine Forge Press.

Friedman, Joseph, George Karandinos, Laurie K. Hart, Fernando M. Castrillo, Nicholas Graetz, and Philippe Bourgois. 2019. Structural vulnerability to narcotics-driven firearm violence: An ethnographic and epidemiological study of Philadelphia's Puerto Rican inner-city. PLoS ONE 14: e0225376. [CrossRef]

Groff, Elizabeth, and Eric S. McCord. 2012. The role of neighborhood parks as crime generators. Security Journal 25: 1-24. [CrossRef]

Haberman, Cory P. 2017. Overlapping hot spots? Examination of the spatial heterogeneity of hot spots of different crime types. Criminology \& Public Policy 16: 633-60. [CrossRef]

Haigler, Nehemiah, and Melissa Francis. 2020. Personal communication.

Han, Ying, Wei Yan, Yongbo Zheng, Muhammad Z. Khan, Kai Yuan, and Lin Lu. 2019. The rising crisis of illicit fentanyl use, overdose, and potential therapeutic strategies. Translational Psychiatry 9: 282. [CrossRef]

Harocopos, Alex, and Mike Hough. 2012. Drug Dealing in Open-Air Markets; Problem-Oriented Guides for Police. Problem Specific Guides Series No. 31; Washington, DC: Department of Justice Office of Community Oriented Policing Services.

Headley Konkel, Rebecca, and Chrystina Y. Hoffman. 2020. Immediate and neighborhood contextual effects on intentional, accidental, and fatal drug overdoses in a non-urban jurisdiction. Deviant Behavior 1-18. [CrossRef]

Hembree, C, Sandro Galea, Jennifer Ahern, Melissa Tracy, T. Markham Piper, J. Miller, David Vlahov, and Kenneth J. Tardiff. 2005. The urban built environment and overdose mortality in New York City neighborhoods. Health \& Place 11: 147-56. [CrossRef]

Hsu, Ko-Hsin, and Joel Miller. 2017. Assessing the situational predictors of drug markets across street segments and intersections. Journal of Research in Crime and Delinquency 54: 902-29. [CrossRef]

Johnson, Lallen T. 2016. Drug markets, travel distance, and violence: Testing a typology. Crime E Delinquency 62: 1465-87. [CrossRef]

Johnson, Lallen T., and Tayler Shreve. 2020. The ecology of overdose mortality in Philadelphia. Health E Place 66: 102430. [CrossRef]

Li, Zehang R., Evaline Xie, Forrest W. Crawford, Joshua L. Warren, Kathryn McConnell, J. Tyler Copple, Tyler Johnson, and Gregg S. Gonsalves. 2019. Suspected heroin-related overdoses incidents in Cincinnati, Ohio: A spatiotemporal analysis. PLoS Medicine 16: 1-15. [CrossRef] [PubMed]

Lieberman, Dan, Sean Ryon, and Ed Ou. 2020. With Overdose Deaths up during the Pandemic, Philadelphia Fights for a Legal Safe Injection site. NBC News. August 2. Available online: https://www.nbcnews.com/news/usnews/overdose-deaths-during-pandemic-philadelphia-fights-legal-safe-injection-site-n1235583 (accessed on 29 September 2020).

Martinez, Ramiro, Jr., Richard Rosenfeld, and Dennis Mares. 2008. Social disorganization, drug market activity, and neighborhood violent crime. Urban Affairs Review 43: 846-74. [CrossRef]

Mazerolle, Lorraine, David Soole, and Sacha Rombouts. 2007. Drug law enforcement: A review of the evaluation literature. Police Quarterly 10: 115-53. [CrossRef]

McCord, Eric S., and Jerry H. Ratcliffe. 2007. A micro-spatial analysis of the demographic and criminogenic environment of drug markets in Philadelphia. Australian \& New Zealand Journal of Criminology 40: 43-63. [CrossRef]

Mennis, Jeremy, Gerald J. Stahler, and Michael J. Mason. 2016. Risky substance use environments and addiction: A new frontier for environmental justice research. International Journal of Environmental Research and Public Health 13: 607. [CrossRef] [PubMed] 
Metraux, Stephen, Meagan Cusack, Fritz Graham, David Metzger, and Dennis Culhane. 2019. An evaluation of the City of Philadelphia's Kensington Encampment Resolution Pilot. Available online: https://www.phila.go v/media/20190312102914/Encampment-Resolution-Pilot-Report.pdf (accessed on 29 September 2020).

NIDA (National Institute on Drug Abuse). 2020. Pennsylvania: Opioid-Involved Deaths and Related Harms. Available online: https://www.drugabuse.gov/drug-topics/opioids/opioid-summaries-by-state/pennsylvania -opioid-involved-deaths-related-harms (accessed on 29 September 2020).

Olsen, Yngvild. 2016. The CDC guideline on opioid prescribing: Rising to the challenge. JAMA 315: 1577-79. [CrossRef]

Ousey, Graham C., and Charis E. Kubrin. 2018. Immigration and crime: Assessing a contentious issue. Annual Review of Criminology 1: 63-84. [CrossRef]

Pardo, Bryce, Jirka Taylor, Jonathan P. Caulkins, Beau Kilmer, Peter Reuter, and Bradley D. Stein. 2019. The Future of Fentanyl and Other Synthetic Opioids. Santa Monica: RAND Corporation, Available online: https://ntakd.lrv.lt/uploads/ntakd/documents/files/Published\%20version.pdf (accessed on 29 September 2020).

Percy, Jennifer. 2018. Trapped by the 'Walmart of Heroin'. The New York Times Magazine. October 10. Available online: https://www.nytimes.com/2018/10/10/magazine/kensington-heroin-opioid-philadelphia.ht $\mathrm{ml}$ (accessed on 29 September 2020).

Piza, Eric L., and Andrew M. Gilchrist. 2018. Measuring the effect heterogeneity of police enforcement actions across spatial contexts. Journal of Criminal Justice 54: 76-87. [CrossRef]

Police Executive Research Forum. 2016. Building Successful Partnerships between Law Enforcement and Public Health Agencies to Address Opioid Use; COPS Office Emerging Issues Forums. Washington: Office of Community Oriented Policing Services.

Ratcliffe, Jerry H. 2004. Geocoding crime and a first estimate of a minimum acceptable hit rate. International Journal of Geographical Information Science 18: 61-72. [CrossRef]

Ratcliffe, Jerry H., and Travis A. Taniguchi. 2008. Is crime higher around drug-gang street corners? Two spatial approaches to the relationship between gang set spaces and local crime levels. Crime Patterns and Analysis 1: 17-39.

Ratcliffe, Jerry H., Travis Taniguchi, Elizabeth R. Groff, and Jennifer D. Wood. 2011. The Philadelphia foot patrol experiment: A randomized controlled trial of police patrol effectiveness in violent crime hotspots. Criminology 49: 795-831. [CrossRef]

Roman, Caterina G., and Shannon E. Reid. 2012. Assessing the relationship between alcohol outlets and domestic violence: Routine activities and the neighborhood environment. Violence and Victims 27: 811-28. [CrossRef] [PubMed]

Roman, Caterina G., Shannon E. Reid, Avinash S. Bhati, and Bogdan Tereshchenko. 2008. Alcohol Outlets as Attractors of Violence and Disorder: A Closer Look at the Neighborhood Environment. Washington, DC: Urban Institute.

Roselli, Vito. 2018. The Violent Crime E Opioid Reduction Partnership (VCORP), Kensington; Philadelphia: FBI Philadelphia, Pennsylvania Office of the Attorney General, Philadelphia Police Department, Unpublished Report (June).

Rudd, Rose A., Noah Aleshire, Jon E. Zibbell, and R. Matthew Gladden. 2016. Increases in drug and opioid overdose deaths-United States, 2000-2014. Morbidity and Mortality Weekly Report 64: 1378-82. [CrossRef]

Schwartz, David G., Janna Ataiants, Alexis Roth, Gabriela Marcu, Inbal Yahav, Benjamin Cocchiaro, Michael Khalemsky, and Stephen Lankenau. 2020. Layperson reversal of opioid overdose supported by smartphone alert: A prospective observational cohort study. EClinical Medicine 25: 100474. [CrossRef]

Shaw, Clifford R., and Henry D. McKay. 1942. Juvenile Delinquency and Urban Areas. Chicago: The University of Chicago Press.

St. Jean, Peter K.B. 2007. Pockets of Crime: Broken Windows, Collective Efficacy, and the Criminal Point of View. Chicago: University of Chicago.

Stevens, Alex, and Dave Bewley-Taylor. 2009. Drug Markets and Urban Violence: Can Tackling one Reduce the Other? Report 15. Oxford: The Beckley Foundation Drug Police Programme, pp. 1-15.

Taniguchi, Travis A., George F. Rengert, and Eric S. McCord. 2009. Where size matters: Agglomeration economies of illegal drug markets in Philadelphia. Justice Quarterly 26: 670-94. [CrossRef] 
Taniguchi, Travis A., Jerry H. Ratcliffe, and Ralph B. Taylor. 2011. Gang set space, drug markets, and crime around drug corners in Camden. Journal of Research in Crime and Delinquency 48: 327-63. [CrossRef]

Tita, George E., Jacqueline Cohen, and John Engberg. 2005. An ecological study of the location of gang "set space". Social Problems 52: 272-99. [CrossRef]

Topalli, Volkan, Richard Wright, and Robert Fornango. 2002. Drug dealers, robbery and retaliation: Vulnerability, deterrence and the contagion of violence. British Journal of Criminology 42: 337-51. [CrossRef]

Trangenstein, Pamela J., Frank C. Curriero, Daniel Webster, Jacky M. Jennings, Carl Latkin, Raimee Eck, and David H. Jernigan. 2018. Outlet type, access to alcohol, and violent crime. Alcoholism: Clinical and Experimental Research 42: 2234-45. [CrossRef] [PubMed]

Valasik, Matthew. 2018. Gang violence predictability: Using risk terrain modeling to study gang homicides and gang assaults in East Los Angeles. Journal of Criminal Justice 58: 10-21. [CrossRef]

Valasik, Matthew, and George Tita. 2018. Gangs and space. In The Oxford Handbook of Environmental Criminology. Edited by Gerben Bruinsma and Shane Johnson. Oxford: Oxford University Press. [CrossRef]

Weisburd, David, Lorraine Green, Frank Gajewski, and Charlie Bellucci. 1994. Defining the street-level drug market. In Drugs and Crime: Evaluating Public Policy Initiatives. Edited by D. L. MacKenzie and C. D. Uchida. Thousand Oaks: Sage, pp. 61-76.

Weisburd, David, Elizabeth R. Groff, and Sue-Ming Yang. 2010. Understanding Developmental Crime Trajectories at Places: Social Disorganization and Opportunity Perspectives at Micro Units of Geography; Washington: National Institute of Justice.

Wheeler, Andrew P. 2018. The effect of 311 calls for service on crime in DC at microplaces. Crime E Delinquency 64: 1882-903. [CrossRef]

Whelan, Aubrey. 2020. Philly's Overdose Deaths Rose again in 2019, Especially in Black and Latino Communities. Philadelphia Inquirer. May 13. Available online: https://www.inquirer.com/health/opioid-addiction/philadelp hia-overdose-deaths-2019-rise-20200513.html (accessed on 29 September 2020).

Whyte, William F. 1955. Street Corner Society: The Social Structure of an Italian Slum. Chicago: University of Chicago Press.

Wolfram, Joel. 2017. Philly Briefs Neighborhood on Cleanup of Conrail Heroin Encampment. WHYY, June 20. Available online: https://whyy.org/articles/philly-briefs-neighborhood-on-cleanup-of-conrail-heroin-enca mpment (accessed on 29 September 2020).

Publisher's Note: MDPI stays neutral with regard to jurisdictional claims in published maps and institutional affiliations.

(C) 2020 by the authors. Licensee MDPI, Basel, Switzerland. This article is an open access article distributed under the terms and conditions of the Creative Commons Attribution (CC BY) license (http://creativecommons.org/licenses/by/4.0/). 